\title{
REFLEXÃO DOCENTE SOBRE AVALIAÇÃO DOS ESTUDANTES COM DEFICIÊNCIA NO ENSINO SUPERIOR
}

\author{
Vanderlei Balbino Costa ${ }^{1}$
}

\begin{abstract}
Resumo: Ao referirmos à educação especial das pessoas com deficiência, o fenômeno da avaliação se torna complexo, na medida em que não sabemos efetivamente o que avaliar, como avaliar e por que avaliar? O estudo é resultado de investigação junto a dez docentes de algumas licenciaturas na Regional Jataí. A questão de pesquisa foi: como os docentes do ensino superior avaliam os estudantes com deficiência? Objetivos: analisar se os discursos sobre avaliação, expressos pelos docentes, têm contribuído para o processo de inclusão dos estudantes com deficiência no ensino superior; avaliar se os recursos didáticos, utilizados pelos docentes no ensino superior, vêm contribuindo para o processo de inclusão escolar dos estudantes com deficiência matriculados; identificar se as práticas avaliativas, empregadas pelos docentes no ensino superior, têm a intenção de comparar o nível de aprendizagem dos estudantes com deficiência aos demais estudantes; discutir à luz dos referenciais teóricos se os professores do ensino superior fazem avaliação comparativa para os estudantes com deficiência. A opção foi pela pesquisa qualitativa, apoiando-nos na análise do discurso de linha francesa. O marco teórico priorizou autores que discutem a avaliação dos estudantes com deficiência em uma perspectiva inclusiva. Os resultados nos mostraram que o processo de avaliação ainda não está resolvido junto aos professores que atuam no ensino superior, uma vez que os depoimentos demonstraram que não há uma definição clara sobre o processo de avaliação, em especial, quando nos referimos aos estudantes com deficiência matriculados no ensino superior. Nossas considerações, que não são conclusivas, nos fizeram refletir sobre a necessidade de se investir na formação docente, quando se refere a avaliação dos estudantes com deficiência na escola comum.
\end{abstract}

Palavras-chave: Ensino superior. Avaliação docente. Estudantes com deficiência.

\section{TEACHER REFLECTION ON EVALUATION AND ASSESSMENT OF DISABLED STUDENTS IN HIGHER EDUCATION}

\begin{abstract}
When we refer to special education of people with disabilities, the phenomenon of evaluation turns out to be rather complex, since we do not know effectively what to evaluate, how to evaluate and why to evaluate. This study is the result of a research with ten professors of some undergraduate degree courses in the UFG - Universidade Federal de Goiás, Regional Jataí. The research question was: how do higher education teachers evaluate students with disabilities? Objectives: to analyze whether evaluation discourses expressed by professors

\footnotetext{
${ }^{1}$ Possui graduação em Licenciatura Plena em História pela Universidade Federal de Mato Grosso (1992), mestrado em Educação pela Universidade Federal de São Carlos (2009), doutorado em Educação Especial pela Universidade Federal de São Carlos (2012). Professor adjunto da Universidade Federal de Goiás, Campus Jataí , Coordenação de Pedagogia.
} 


\section{Hetrianiums REFLECTIONIS

Volume, 14, número 1, 2018.

have contributed to the process of inclusion of disabled students in higher education; to analyze if the didactic resources used by the teachers in higher education has been contributing to the process of school inclusion of disabled students enrolled; to identify if evaluation practices, used by teachers in higher education, aim to compare the level of learning of disabled students to other students; to discuss, in the light of theoretical references, if higher education teachers make comparative assessment for students with disabilities. The option was the qualitative research, supported in the analysis of the French line discourse. The theoretical framework prioritized authors who discuss the evaluation of students with disabilities in an inclusive perspective. Results showed that the evaluation process has not yet been solved with teachers who work in higher education, since the declarations showed that there is no clear definition of the evaluation process, especially when we refer to students with disabilities enrolled in higher education. Our considerations, which are not conclusive, have made us reflect on the need to invest in teachers' continued formation, when it refers to the assessment and evaluation of disabled students in the regular school.

Keywords: Higher education. Teacher assessment. Disabled students.

\section{INTRODUÇÃO}

\section{Aspectos Históricos}

Historicamente, desde a antiguidade clássica, Grécia e Roma, as pessoas com deficiência eram abandonadas, rejeitadas, jogadas aos abismos sem dó, pena e piedade. Excluir, marginalizar e estigmatizar foi ao longo de séculos, uma marca perversa daqueles que acreditavam que a sociedade deveria ser constituída por bons, normais, perfeitos e bem constituídos.

Os processos excludentes nas sociedades antigas eram tão avassaladores que crianças com deficiência eram consideradas como seres sobrenaturais. Frente a essa assertiva Ferreira; Guimarães (2003, p. 65) assinalam que "Na Antiguidade Clássica e na Idade Média, a explicação para deficiência estava frequentemente atrelada a crenças sobrenaturais, demoníacas e supersticiosas".

Neste modelo de rejeição, Amaral (1990, p. 30-31) vislumbra-se a política do avisstruthio, que significa:

O avestruz-sociedade enfia a cabeça na areia, isolando o "estranho", o deficiente, seja criando ativamente locais de confinamento, seja esperando que esse ser desconfortável tenha a "gentileza" de tornar-se invisível para os olhos sensíveis, "recolhendo-se à sua insignificância", modestamente colocando-se em "seu devido lugar" - o mais longe possível dos cidadãos comuns. 


\section{IytriaAinus

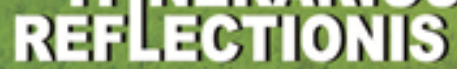

Volume, 14, número 1, 2018.

Se reportarmos aos romanos no início da Era Cristã, a aceitação social das pessoas com deficiência era marcada por traços de crueldade. Partindo dessa premissa Misés (1977, p. 14) afirma que: animais e crianças eram sacrificados utilizando o seguinte discurso:

Nós matamos os cães danados e touros ferozes, degolamos ovelhas doentes, asfixiamos recém-nascidos mal constituídos; mesmo as crianças se forem débeis ou anormais, nós as afogamos, não se trata de ódio, mas da razão que nos convida a separar das partes sãs aquelas que podem corrompê-las.

Se guinarmos nosso olhar para o mundo ocidental, é público e notório perceber que, foi somente a partir do século XVI que se iniciaram efetivamente os primeiros passos a fim de prestar serviços às pessoas com deficiência. De acordo com Ferreira (1994), no ocidente, o atendimento às pessoas com necessidades especiais começou quando a questão da anormalidade pela deficiência passou a ser estudo da medicina.

Não obstante, ao se referir ao atendimento às pessoas com deficiência, foi somente no século XX que surgiram na América do Norte e nos Países Escandinavos, as primeiras escolas com caráter de reabilitar e integrar aqueles que tinham deficiência. Cumpre-nos aqui acentuar que, em essência a meta ainda era excluir, segregar, marginalizar e esconder esses seres do convívio social.

\section{PROBLEMA DE PESQUISA}

No atual modelo educacional que temos, os processos de exclusão/marginalização se dão por outras formas, como por exemplo, os processos de avaliação que, para muitos docentes, devem ser comparativos, como se fosse possível aprender no mesmo ritmo, da mesma forma, do mesmo jeito, enfim, ao mesmo tempo. Partindo dessa premissa, o problema de pesquisa que suleou nossa investigação foi: como os docentes do ensino superior avaliam os estudantes com deficiência?

\section{OBJETIVOS}


Volume, 14, número 1, 2018.

Os objetivos do estudo foram: analisar se os discursos sobre avaliação, expressos pelos docentes, têm contribuído para o processo de inclusão dos estudantes com deficiência no ensino superior; avaliar se os recursos didáticos, utilizados pelos docentes no ensino superior, vêm contribuindo para o processo de inclusão escolar dos estudantes com deficiência matriculados; identificar se as práticas avaliativas, empregadas pelos docentes no ensino superior, têm a intenção de comparar o nível de aprendizagem dos estudantes com deficiência aos demais estudantes; discutir à luz dos referenciais teóricos se os professores do ensino superior fazem avaliação comparativa para os estudantes com deficiência.

\section{REFERENCIAL TEÓRICO}

Obviamente sabemos que a avaliação ainda é um fenômeno complexo no processo de ensino e de aprendizagem. Partindo dessa premissa, é de fundamental importância assinalar que, historicamente, no Brasil, o discurso sobre a inclusão escolar das pessoas com deficiência começou a se consolidar nos anos de 1990, quando foram realizadas diversas convenções internacionais, como por exemplo a Declaração Mundial de Educação Para Todos (UNESCO, 1990) e a Declaração de Salamanca (UNESCO, 1994).

Quando referimos ao Brasil, é profícuo assinalar que, o marco principal da inclusão foi a aprovação da LDBEN (9394/96), que pela primeira vez fez aprovar um capítulo específico sobre a Educação Especial em uma perspectiva inclusiva.

No que concerne à avaliação dos estudantes com deficiência, transtornos globais do desenvolvimento, altas habilidades e superdotação, sabemos que há pelos docentes, dúvidas de como fazer uma avaliação com esse público, visto que alegam esses docentes, que não foram preparados para essa tarefa.

O trabalho docente sempre enfrentou dificuldades, dúvidas e questionamentos, quando nos referimos à avaliação da aprendizagem. Isso se torna mais evidente quando outros sujeitos surgem no cenário da educação, o público do ensino especial. Essa premissa é observada por Sartoretto (2010, p. 1) ao assinalar que: "A avaliação sempre foi uma pedra no sapato do trabalho docente do professor. Quando falamos em avaliação de alunos com deficiência, então, o problema torna-se mais complexo ainda". O discurso de que a avaliação é uma prática complexa se justifica, a nosso ver, na medida em que na formação inicial, nas 


\section{HyfFiaAitus RA;

Volume, 14, número 1, 2018.

licenciaturas, quase não vemos conteúdos que nos embasem teoricamente para que essa prática não se configure em um calo nos nossos calcâneos.

Não é fácil avaliar se os estudantes aprendem fazendo uma avaliação comparativa mediada pela quantificação de uma nota ou de um conceito. Partindo dessa premissa Valentim; Oliveira (2013) assinalam que é muito difícil avaliar, porque as vezes, não sabemos o que avaliar? como avaliar? e quem deve ser avaliado? As autoras nos alertam que a ação de avaliar deve servir para que possamos perceber o movimento, procurando apontar caminhos para uma ação no processo educativo.

É obvio que o enigma da avaliação da aprendizagem ainda se configura como um fenômeno junto aos docentes. Ao referirmos à inclusão escolar dos estudantes com deficiência, esse processo ainda gera dúvidas, indagações e questionamentos. À luz da literatura especializada que enfatiza essa questão, as Diretrizes Nacionais para a Educação Especial na Educação Básica - Brasil (2001, p. 34) definiu:

a avaliação pedagógica dos alunos como processo permanente de análise das variáveis que interfere no processo de ensino e aprendizagem, para identificar potencialidades e necessidades educacionais dos alunos e as condições da escola para responder a essas necessidades.

Estava aí, dada a largada para que docentes, coordenadores pedagógicos e gestores, passassem a olhar para a avaliação dos estudantes com deficiência de forma diferente.

Em um processo educativo, pensamos que ao docente caberá alguns desafios, como: acompanhar cotidianamente o desempenho dos educandos em seu processo de aquisição do saber; propor recursos didáticos diferenciados de modo a diagnosticar diferentes ritmos de aprendizagem; refletir sobre a adequação do currículo, adaptando-os às diferentes necessidades educativas especiais. Esses desafios, por nós mencionados, é partilhado por André (1999) ao afirmar que é por meio da avaliação, que o professor poderá acompanhar o processo de aprendizagem dos estudantes e ao mesmo tempo, monitorar o seu ensino, realizando uma investigação didática. De posse dessa investigação, seguramente o professor poderá diagnosticar se seu planejamento, os recursos didáticos utilizados e a adequação do currículo, tiveram resultados positivos ou negativos. 


\section{HyfFiaAitus

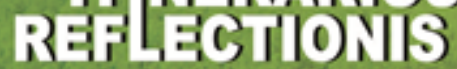

Volume, 14, número 1, 2018.

Embora não aparente a avaliação da aprendizagem, ainda se configura para os educandos como um castigo para compensar e corrigir os erros cometidos por eles no decorrer do processo educativo. Essa premissa é partilhada por Luckesi (2008 p. 49) ao assinalar que

hoje as formas de castigar são raras; porém, o castigo não desapareceu da escola. Ele se manifesta de outras maneiras, que não atingem imediatamente o corpo físico do aluno, mas sua personalidade, sendo no sentido em que Bourdieu fala em seu livro a reprodução. Uma "violência simbólica".

Em plena era da globalização, do mundo das redes, enfim, das tecnologias avançadas, ainda vemos no sistema educacional, profissionais da educação que insistem em fazer da avaliação um mecanismo de coerção, punição e castigo àqueles alunos que não se encaixam nos padrões de homogeneidade. Frente ao exposto Christofari $(2012$, p. 1) levanta algumas indagações: "É possível mensurar o conhecimento? É possível saber o quanto sabemos? É possível sabermos o quanto o outro sabe?" Essas indagações nos fazem refletir que, ao se referir o processo de ensino e aprendizagem, não é possível medir, quantificar e/ou avaliar numericamente peso ou valor do quanto nossos educandos apreenderam no decorrer do ano letivo.

Sabemos que não há um modelo de avaliação perfeito, pronto e acabado. No entanto, quando referimos aos ciclos de formação, aventa-se a possibilidade de se implementar na escola, algumas maneiras de avaliar sem que promovemos a exclusão e marginalização daqueles alunos que não estão encaixados nos modelos homogêneos. Frente a essa assertiva Christofari (2012, p.10) assinala que:

\footnotetext{
nas redes de ensino organizadas por propostas embasadas nos ciclos a avaliação da aprendizagem se caracteriza por conceber essa prática como processual, contínua, participativa e investigativa. Pensando nessa perspectiva faz-se necessário questionar se é possível a avaliação da aprendizagem se constituir como ação pedagógica de favorecimento do processo de inclusão? É possível construir uma avaliação inclusiva?
}

Esta tríplice indagação nos faz pensar que é possível fazer uma avaliação inclusiva, desde que não avaliemos utilizando de critérios comparativos. 
Volume, 14, número 1, 2018.

\section{MÉTODO}

Nossa opção nesse estudo reflexivo foi pela pesquisa qualitativa. Para tanto, apoiamo-nos em Lüdke; André (1986, p. 11) ao mencionarem que: "a pesquisa qualitativa tem o ambiente natural como sua fonte direta de dados e o pesquisador como seu principal instrumento".

Por se tratar de uma pesquisa qualitativa, pautada no discurso expresso pelos docentes sobre o processo de avaliação dos estudantes com deficiência, o método empregado nesse estudo foi a análise do discurso de linha francesa, fundamentando em autores como Orlandi (2005); Foucault (2006); Pêcheux (2006) dentre outros

Obviamente, não é nossa intenção discutir, nem ao menos conceituar, o que é análise do discurso neste estudo. No entanto, para Gomes (2006, p. 626), o discurso pode ser entendido como "o enunciado formulado em certas condições de produção, determinando um certo processo de significação [...]. O discurso não é apenas transmissão de informação, mas efeito de sentido entre interlocutores". Considerando este conceito, queremos dizer que no decorrer da pesquisa, os discursos analisados envolvendo os sujeitos entrevistados demonstraram que não está claro o que estes pensam sobre a avaliação dos estudantes com deficiência no ensino superior.

Considerando o método proposto neste estudo investigativo, optamos em fazer uma análise do discurso dos docentes sobre o que estes pensam acerca da avaliação de estudantes com deficiência incluídos no ensino superior. Neste sentido, Dubois (1995) citado por Orlandi (2005), assinala que a análise do discurso é pensada como a passagem natural dos estudos das palavras aos estudos do enunciado, permitida pela linguística. Por sua vez, Pêcheux (1997), revela que a análise do discurso é considerada uma ruptura epistemológica com a ideologia que domina as ciências humanas.

Cumpre-nos aqui ressaltar que os participantes da pesquisa foram docentes que atuam no ensino superior, ministrando aulas nos cursos de licenciaturas, formando professores para a educação básica, na qual os novos sujeitos formados vão se ingressar.

Ao planejar a pesquisa, seus procedimentos e os instrumentos para coletar os dados, lançamos mão de dois procedimentos metodológicos, a saber: o início do ano letivo, aproximamos dos professores nas horas de seus planejamentos pedagógicos ou coletivos nas 
Volume, 14, número 1, 2018.

reuniões do colegiado, a fim de conhecer o que estes pensam sobre o processo de avaliação dos estudantes com deficiência no ensino superior; em outro momento, convidamos para participar de alguns diálogos sobre o que pensam, como fazem as avaliações em sua sala de aula, em especial, quando nessas há presença de alunos com deficiência no ensino superior.

Os instrumentos para coleta dos dados se consubstanciaram em entrevistas do tipo semiestruturadas, aqui entendidas por Triviños (1987, p. 152) como: "[...] favorece não só a descrição dos fenômenos sociais, mas também a sua explicação e a compreensão de sua totalidade". Considerando a necessidade de compreendermos melhor o fenômeno da avaliação, intencionamos discutir à luz dos referenciais, como esse processo vem se dando no ensino superior, quando referimos o processo de inclusão dos estudantes com deficiência.

\section{RESULTADOS E DISCUSSÃO}

Ao se referir ao processo de avaliação nas escolas, somos levados a fazer algumas reflexões: o que devemos avaliar, quando temos a clareza que os nossos estudantes com deficiência, encontram-se matriculados em cursos, cuja preparação docente não ocorreu ao longo de sua formação? como avaliar os estudantes com deficiência, se os docentes no decorrer de sua formação alegam que não estão preparados para a árdua missão de avaliar? por que avaliar, se nem sequer iniciamos o processo de avaliação da nossa própria prática pedagógica em uma sala de aula, frequentada por estudantes com deficiência?

Essas reflexões nos demonstram na medida em que não sabemos ao certo se existe uma real fórmula para avaliar aqueles estudantes, com ou sem deficiência, que buscam nos bancos escolares sua emancipação política.

Após a elaboração do documento intitulado "A política nacional da educação especial na perspectiva da educação inclusiva" BRASIL (2008), este passou a direcionar novos rumos à educação especial, quando preconiza aspectos educativos possibilitadores na avaliação como: o reconhecimento e valorização não apenas do nível que os alunos adquirem no decorrer do processo educativo, mas também, o conhecimento prévio advindo de sua realidade; o professor necessariamente deve criar mecanismos, recursos e estratégias de modo a facilitar que os alunos possam sobressaírem diante dos processos avaliativos; aos docentes envolvidos no processo de ensino e aprendizagem, caberá atentar para a questão do tempo, 


\section{HyfFiaAitus RA;

Volume, 14, número 1, 2018.

quando em suas salas, há a presença de estudantes com deficiência diversas como surdos, usuário da libras, cegos, quando utilizam o sistema braile, ou mesmo os estudantes que lançam mão das tecnologias assistivas.

Analisando os discursos dos docentes, constatamos que não há entre os entrevistados, consenso em relação a avaliação dos estudantes com deficiência. Neste sentido, indagamos uma das docentes: você faz avaliação diferenciada para os estudantes com deficiência? A docente 1, em seu depoimento acentuou: "devido eles serem deficientes, possuir limitações físicas, intelectuais, auditivas... eu penso que essa avaliação precisa ser diferenciada, e que a cobrança deve ser menor, menos rigorosa em comparação com os demais alunos considerados normais". À luz da literatura especializada que enfatiza essa questão, Costa (2012) contesta afirmando que não é a avaliação que tem que ser diferenciada, mas sim, os recursos didáticos, os métodos, as estratégias e o currículo que precisa ser adequado às diferentes necessidades educativas especiais.

Os processos de avaliação que temos são complexos, porque os docentes insistem em fazer avaliações comparativas, como se fosse possível medir o grau de conhecimento entre os alunos com e sem deficiência. Se reportarmos aos escritos de Sartoretto (2010, p. 1) é necessário eliminarmos alguns aspectos como:

\footnotetext{
- o vínculo a um resultado previamente determinado pelo professor; - o estabelecimento de parâmetros com os quais as respostas dos alunos são sempre comparadas entre si, como se o ato de aprender não fosse individual; - o caráter de controle, adaptação e seleção que a avaliação desempenha em qualquer nível;

- a lógica de exclusão, que se baseia na homogeneidade inexistente;

- a eleição de um determinado ritmo como ideal para a construção da aprendizagem de todos os alunos.
}

Ao agir assim, os docentes partem do princípio de que todos os alunos aprendem no mesmo ritmo, no mesmo tempo, do mesmo jeito, enfim, da mesma forma, como se fôssemos máquinas programadas para produzir em série. Isso é um dos mais graves equívocos pedagógicos cometidos pelos docentes.

Ao indagarmos a docente 6 , se a mesma avalia os estudantes com deficiência do mesmo jeito que os demais, a mesma assim se manifestou: 


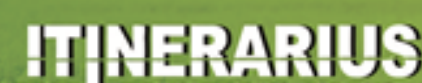

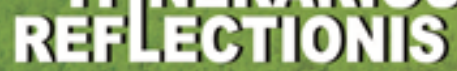

Volume, 14, número 1, 2018.

a avaliação dos alunos com deficiência deve ser igual aos demais, pois , se eles estão incluídos, na mesma sala, assim como os colegas considerados normais, terei que avaliá-los do mesmo jeito, porque senão, estarei promovendo discriminação entre os que são normais e os que são especiais.

$\mathrm{Na}$ nossa concepção, os nós do processo avaliativo, não estão em avaliar os estudantes com deficiência de forma igual ou diferente dos demais. O problema, a nosso ver, é elaborar uma avaliação que possa identificar se os sujeitos da educação especial alcançaram êxito em seu processo educativo.

Não sei se é pela falta de formação inicial e continuada dos docentes, que há por eles ansiedade no que concerne o ritmo de aprendizagem dos alunos, em especial, quando o alvo é a avaliação dos que têm deficiência. Dialogando com uma das nossas entrevistadas sobre avaliação no ensino superior, quando neste há estudantes com deficiência, a mesma assim se manifestou: "as crianças, jovens ou mesmo adultos não aprendem de forma homogênea, ou seja, eles têm ritmos diferentes em seu processo de ensino e apreensão do conhecimento". A docente está correta em afirmar que as pessoas com deficiência têm ritmos e tempos diferentes para aprender em relação àqueles que não apresentam nenhuma deficiência.

As dificuldades para a promoção da inclusão escolar, está na formação inicial dos novos docentes nas licenciaturas, bem como, a necessidade de se rever a prática pedagógica desses novos sujeitos que estão adentrando no mercado de trabalho, cuja intenção, é atuar na sala de aula, quando nessa, registra-se a presença dos estudantes com deficiência. Diante dessa assertiva Pletsch (2014) assinala que a formação docente, no contexto das políticas de inclusão escolar, deve ser fundamentada em conhecimentos que façam a necessária articulação entre o "micro" e o "macro" contexto social, político e econômico. Igualmente, entendemos ainda, que não basta implementar políticas de inclusão sem oferecer aos docentes, reais condições para atender seus alunos com deficiência, transtornos globais do desenvolvimento e altas habilidades. O que a autora quer nos alertar, é que precisamos elaborar políticas de inclusão, articuladas e associadas obviamente a formação inicial e continuada dos novos docentes que estão ingressando no mercado de trabalho. 


\section{Hellizainus RA;

Volume, 14, número 1, 2018.

Em qualquer ação pedagógica, não há formas tecnicistas, mecânicas e/ou milagrosas que possam formar bem o professor em sua atuação profissional. A formação inicial e continuada, a nosso ver, precisa ser alvo desse processo. De acordo com Jesus (2004) é de fundamental importância uma preparação que estimule o professor ser reflexivo em sua prática profissional, pois, quando refletimos a nossa atuação, pensamos a escola, como essa se organiza, seguramente, estamos aventando para a possibilidade de construir no processo de aprendizagem, uma avaliação capaz de acompanhar de forma holística o desenvolvimento intelectual dos educandos, seus ritmos diferentes, passos importantes rumo à apreensão do conhecimento científico e do saber elaborado.

$\mathrm{Na}$ atual conjuntura política, na qual nos encontramos, não é possível pensar que o conhecimento já está pronto e acabado. Também não é aceitável que o professor, a escola e as instituições, que gestam o sistema educacional, não precisam se renovar constantemente. Essa premissa é partilhada por Alarcão (2001 p. 24) ao assinalar que "[...] há uma exigência do professor a consciência de que a sua formação nunca está terminada e das chefias e do governo, a assunção do princípio de formação continuada". Os escritos da autora nos revelam que a formação dos professores precisa estar ladeada de um conjunto de ações políticas, que objetive a difusão do conhecimento para todos os educandos, sejam eles, com e sem deficiência, incluídos na escola comum.

No decorrer das entrevistas a docente 10 foi por nós questionada sobre quais critérios a mesma utiliza para avaliar os estudantes com deficiência no ensino superior. Nessa busca investigativa, conseguimos aferir que a docente anunciou aquilo que pretendíamos ouvir:

[...] eu penso que não devo avaliar os alunos com deficiência do mesmo jeito que os que são considerados normais, pois eles têm ritmos e tempos diferentes que os outros. Assim, minha avaliação para eles será feita de acordo com o desenvolvimento ou desempenho de cada um, até porque eles aprendem mais devagar que os colegas da turma.

Esse depoimento é partilhado por Lopes (2010) ao assinalar que os estudantes com deficiência devem ser avaliados de acordo com seu desempenho e nunca por critérios comparativos. 


\section{Hellizainus

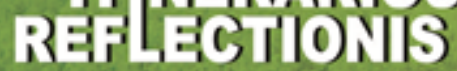

Volume, 14, número 1, 2018.

Ao analisar os resultados expressos na conclusão dessa pesquisa, conseguimos aferir que, diante do processo de ensino e aprendizagem, não é possível fazer avaliação homogênea, igualitária, enfim, comparativa. Frente a essa assertiva, Perrenoud (1999) assinala que os professores devem romper com esse esquema igualitarista. Para o autor, não há razão alguma de dar a todos os estudantes a mesma dose de avaliação formativa. Pensamos que as diferentes formas de observar e interpretar o processo educativo dos estudantes, obviamente observando suas necessidades educativas especiais em contextos inclusivos.

À luz dos referenciais, os resultados nos mostraram que, para muitos docentes, a meta e/ou objetivos da avaliação ainda é a de alcançar o produto e não o processo educativo, ou seja, preocupamos muito mais com as notas dos alunos, com aquilo que eles não sabem fazer, do que aquilo que eles já fazem sozinhos, de forma autônoma e com independência educativa.

Ao concluirmos essa pesquisa, os resultados alcançados demonstraram que desde 2001, já havia pelas instituições educacionais, bem como, pelos que gestam a educação especial em uma perspectiva inclusiva, a preocupação em criar um mecanismo de avaliação capaz de avaliar, sem excluir e marginalizar. A problemática, a nosso ver, é que grande parte desses documentos, não esclarecem o público leitor como devemos compreender a avaliação no âmbito da educação inclusiva.

\section{CONCLUSÕES}

As conclusões aqui expressas, não são finais. Elas são, considerações reflexivas, questionadoras, que nos incomodam, na medida em que ainda se depara nas escolas brasileiras, inclusive no ensino superior com modelos de avaliação arcaico, ultrapassado, tradicional, principalmente, quando vivenciamos nas instituições, em todos os níveis, avaliações descontextualizadas, limitadoras, engessadas, capazes de punir, castigar, penalizar os alunos, quando o correto, seria, a nosso ver, propor uma avaliação libertadora, humanizada, não de torturar, mas sim, de emancipar. Não cremos, nem ao menos defendemos que as avaliações tenham a intenção de castigar, punir e penalizar. Cremos que falta para os docentes, processos formativos no que concerne essa prática educativa. 


\section{Hellizainus

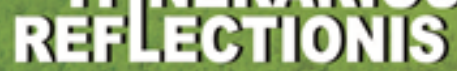

Volume, 14, número 1, 2018.

Na nossa concepção, não basta implementar políticas que preconizam à educação inclusiva sem oferecer aos docentes, condições pedagógicas como: atendimento educacional especializado, parcerias institucionais, trabalho colaborativo, cooperação entre docentes do ensino comum e do ensino especial e formação inicial e continuada, para que ao se deparar na sala de aula com estudantes deficientes, os docentes possam se sentir desafiados frente as ações inclusivas.

Nossas reflexões sobre os processos avaliativos dos alunos com e sem deficiência nas escolas em todos os níveis de aprendizagem, torna-se um grande desafio. Nesse sentido, Sartoretto (2010) observa que, entender quais são as reais finalidades das avaliações nas escolas, só será possível, quando conseguirmos formar professores que estão dispostos a aceitarem esses novos desafios, reconhecer os erros e repensar que a avaliação na educação, não pode e jamais poderá ser vista como produto, mas sim, como processo. Pensamos que o conhecimento dos alunos não pode ser reduzido a capacidade apenas de identificar questões previamente definidas, julgadas pelos professores como certas ou erradas. Isso, a nosso ver, não é aprendizagem, no máximo, isso é produtivismo mecanicista, prática que jamais poderá ser aceita na educação, que em uma perspectiva de Freire (1992) precisa ser "libertadora, humana e humanizante".

Nossas considerações nos fizeram refletir sobre: a avaliação da aprendizagem não serve para medir e quantificar o conhecimento, nem ao menos para diagnosticar se no processo de ensino e aprendizagem, é possível a realização de uma avaliação homogênea em sala de aula.

Ao contrário do que se apregoou durante décadas, na nossa concepção, a avaliação não deve ser, não pode ser e jamais poderá ser, punitiva. Pensamos que diante do processo de ensino e aprendizagem, ela deverá servir de suporte para o desenvolvimento intelectual de todos os estudantes. Ela, a nosso ver, não deve ser utilizada como castigo, mas sim, como decisão suleadora aos caminhos pelos quais o professor deve trilhar para bem conduzir o processo de ensino e aprendizagem.

Hoje, um dos grandes desafios, é inculcar no imaginário docente a ideia de que os estudantes são diferentes, aprendem em ritmos, tempos e modos diferentes. Nesse sentido, desterrar do processo educativo a falseada tese da homogeneização, não se constitui uma 


\section{Intrianitus REF LEstlonis

Volume, 14, número 1, 2018.

tarefa fácil. Ao referir aos estudantes com deficiência, é comum ouvirmos discursos de que é muito difícil avaliar esses sujeitos com deficiência, transtornos globais do desenvolvimento e altas habilidades. Incluir na escola o sujeito com deficiência, propor diferentes formas de avaliação, elaborar diversos recursos didáticos, estratégias de ensino, procedimentos diferenciados, dentre outros, não significa priorizar alguns estudantes. Isso significa, a nosso ver, um ensino onde todos, com e sem deficiência, possam se sentir verdadeiramente incluídos nos diversos seguimentos da escola.

\section{REFERÊNCIAS}

ALARCÃO, Isabel. (Org.). Escola reflexiva e nova racionalidade. Porto Alegre: Artmed, 2001.

AMARAL, Ligia A. Sobre a Questão da Integração: "a política do avis-struthio" e o "leito do procusto". Integração, São Paulo, p. 30-31, 1990.

ANDRÉ, Marli. (Org.) Pedagogia das diferenças na sala de aula. 9. ed. Campinas, SP: Papirus, 1999.

BRASIL. Lei n. 9.394, de 20 de dezembro de 1996. Lei de Diretrizes e Bases da Educação Nacional. Brasília, 1996. Disponível em: < http://www.planalto.gov.br/ccivil_03/leis/ L9394.htm>. Acesso em 23 abr. 2016.

BRASIL. Diretrizes nacionais para a Educação Especial na Educação Básica. MEC SEESP, 2001

BRASIL. Política Nacional de Educação Especial na perspectiva da Educação Inclusiva. Brasília, Janeiro de 2008.

CHRISTOFARI, Ana Carolina. Avaliação da aprendizagem e inclusão escolar: relações possíveis. 2012. Disponível em:

http://www.portalanpedsul.com.br/admin/uploads/2012/Educacao_Especial/Trabalho/07_58_ 49_780-7289-1-PB.pdf. Acesso em: 20 abr. 2016.

COSTA, Vanderlei Balbino da. Olhares docentes sobre a inclusão escolar dos estudantes com deficiência na escola comum. 2012. 199 f. Tese (Doutorado em Educação Especial) Universidade Federal de São Carlos (UFSCar), São Carlos, SP, 2012.

FERREIRA, Júlio R. A exclusão da diferença: a educação do portador de deficiência. 2. ed. Piracicaba: UNIMEP, 1994. 
Volume, 14, número 1, 2018.

FERREIRA, Maria E. C.; GUIMARÃES, Marli. Educação Inclusiva. Rio de Janeiro: DP\&A Editora, 2003.

FOUCAULT, Michel. A ordem do discurso. 13. ed. Tradução: Laura Fraga de Almeida Sampaio. São Paulo: Loyola, 2006.

FREIRE, Paulo. Pedagogia da esperança: um reencontro com a pedagogia do oprimido. Rio de Janeiro: Paz e Terra, 1992.

GOMES, Antonio Marcos Tosoli. O desafio da análise de discurso: os dispositivos analíticos na construção de estudos qualitativos. Revista Enfermagem, Rio de Janeiro, v. 14, n. 4, p. 620-626, out./dez. 2006.

JESUS, Denise Meyrelles de. Atuando em contexto: o processo de avaliação numa perspectiva inclusiva. Psicologia \& Sociedade, São Paulo, v. 16, n. 1, p. 37- 49, 2004.

LOPES, Noêmia. 24 respostas para as principais dúvidas sobre inclusão. 2010. Disponível em: < http://gestaoescolar.abril.com.br/formacao/24-respostas-principais-duvidas-inclusao759360.shtml>. Acesso em 16 abr. 2016.

LUCKESI, Cipriano Carlos. Avaliação da aprendizagem escolar: estudos e proposições. 19. ed. São Paulo: Cortez, 2008.

LÜDKE, Menga; ANDRÉ, Marli E. D. A. Pesquisa em Educação: abordagens qualitativas. São Paulo: EPU, 1986

MISÉS, Roger. A criança deficiente mental: uma abordagem dinâmica. Rio de Janeiro: Zahar, 1977.

ORLANDI, Eni Pulcinelli. Análise de discurso: princípios e procedimentos. 5.ed. Campinas, SP: Pontes, 2005.

PÊCHEUX, Michel. Análise automática do discurso (AAD-69). In: GADADET, F.; HAK, T. (Org.). Por uma análise automática do discurso: uma introdução à obra de Michel Pêcheux. Campinas, SP: UNCAMP, 1997. p. 161-162.

PÊCHEUX, Michel. O discurso: estrutura ou acontecimento. 4. ed. Tradução: Eni P. Orlandi. Campinas, SP: Pontes, 2006.

PERRENOUD, Philippe. Avaliação: da excelência à regulação das aprendizagens entre duas lógicas. Porto Alegre: Artes Médicas, 1999.

PLETSCH, Marcia Denise. Repensando a inclusão escolar: diretrizes políticas, práticas curriculares e deficiência intelectual. 2. ed. Rio de Janeiro: NAU/ EDUR, 2014. 


\section{Ithaialius RBF

Volume, 14, número 1, 2018.

SARTORETTO, Mara Lúcia. Como avaliar o aluno com deficiência? 2010. Disponível em: $<$ http://assistiva.com.br/Como_avaliar_o_aluno_com_defici\%C3\%AAncia.pdf $>$. Acesso em: 10 abr. 2016.

TRIVIÑOS, Augusto Nivaldo Silva. Introdução à Pesquisa em Ciências Sociais: a pesquisa qualitativa em educação. São Paulo: Atlas, 1987.

UNESCO. Declaração mundial sobre educação para todos. Plano de ação para satisfazer as necessidades básicas de aprendizagem. Jomtien, Tailândia, 1990. Disponível em:

$<$ http://www.unicef.org/brazil/pt/resources_10230.htm> Acesso em: 20 abr. 2016.

UNESCO. Coordenadoria Nacional para a Integração da Pessoa Portadora de Deficiência (CORDE). Declaração de Salamanca de princípios, política e prática para as necessidades educativas especiais. Brasília: 1994. Disponível em:

$<$ http://portal.mec.gov.br/seesp/arquivos/pdf/salamanca.pdf $>$. Acesso em: 20 abr. 2016.

VALENTIM, Fernanda Oscar Dourado; OLIVEIRA, Ana Augusta Sampaio. Avaliação da aprendizagem e deficiência intelectual na perspectiva de professores do ensino comum.

Diálogo Educacional, Curitiba, v. 13, n. 40, p. 851-871, set./dez. 2013. 